\title{
Future of Mobile Technology
}

\author{
Ibrahim Alkhubaizi
}

\begin{abstract}
In the recent years, there has been a significant revolution in mobile technology and the entire electronics industry. In fact, major technology companies have made significant milestones in the industry such as developing cell phones which can detect the fingerprints of an individual. Also, mobile technology has eased global linkage, and proximity is insignificant because communication can be done from anywhere in the world. Mobile phones have had a significant effect on our culture especially reducing human interaction and making most people spend all their time on their mobile devices. This study, therefore, seeks to determine the impact of mobile technology on culture.
\end{abstract}

Keywords: Mobile Technology, Mobile Phones, Culture.

\section{INTRODUCTION}

A recent study done in 2009 showed that over $73 \%$ of the youth in the United Stated used mobile phones more than 3 hours a day (Kakabadse et al.). This cultural shift was due to the evolution of mobile technology. For instance, the study indicated that students would spend more time on their phones that with their parents. This, therefore, led to a parental disconnect between the students and their parents which had been caused by spending a lot of time on their phones. Also, Rosen argues that most youths spent a lot of time talking on the phone even when walking along the streets. The youth had also minimized social interactions with their peers, and this had affected their social life. This has also presented a challenge in their workplaces because the youth do not embrace teamwork rather they embrace individual work because most of the time they are on their mobile device. This has led to an inadequate workforce thereby, causing employers to be hesitant in employing the new generation.

\subsection{General Background of the study}

There has been a tremendous growth in the mobile telecommunications industry in the past years (Sirpa). As a matter of fact, mobile technology has revolutionized economic growth in Africa and Asia. Mobile technology has eased communication to the western world, and this has made Africans assimilate the west culture of doing this. That has made them leave their culture with the aim of learning the American culture. Most African countries have forgotten their habits and embraced the western world ideas (Katz and Aakhus). Some of the western behaviors copied include: wearing short dresses and tight jeans, drinking alcohol publicly among many behaviors. Most people have condemned this in those regions, but they have all realize that those are the certain effects of mobile technology. Mobile phones have been very convenient for a majority of people, but they have completely changed how people interact in the social domain. When two or more people are engaging in a conversation, it is evident to see that one of them is very busy on the phone. Therefore, in such a case, there can no longer be a healthy discussion. Various researches have been conducted, and it has been concluded that in this present times many people have been addicted to technology.

Smartphones were introduced to the consumer market approximately by Apple the manufacturers of iPhone. A recent survey shows that around $42 \%$ of phone users in the US use smartphones. This has seen positive growth for the developers as well as the economy. The introduction of smartphones also has had a positive impact on the society such as enhancing communication, but it has had some adverse effects on the cultures and individuals as well. Statistics have also shown that $37 \%$ of adults and $60 \%$ of teenagers have confessed to being addicted to their mobile phones. This has, in turn, led to a dramatic drop of cultural norms among people. Adolescents and the youth are no longer respectful because mobile technology has resulted in increasing in moral decay. Evidently, there needs to be a study to show the effects of mobile technology on the culture.

\subsection{Problem statement}

Mobile technology has revolutionized communication and has made the world a global village. However, technology has caused many of its users become addicted to it. For instance, many phone users have been labeled electronic pests because they spend most of their times scrolling their phones. In fact, most individuals would rather forget anything at home, rather than forget their mobile phones. This has led to a cultural decay among many countries. Therefore, the researcher proposes to 
conduct research on the impact of mobile technology on culture.

\subsection{Research Questions}

The central research question of this study is: what is the impact of mobile technology on culture? However, to answer this research question, the following principal sub-questions will be addressed:

- What are the effects of mobile technology on culture?

- How has mobile technology impacted people's social lives?

- Is it acceptable to use mobile devices at all social places?

\subsection{Research Objectives}

Following the research question stated above, the general objective of this study was to determine the impact of mobile technology on culture.

\subsubsection{Secondary Objective}

The secondary aims of this research are two. Firstly, the researcher has taken a keen interest in mobile technology among individuals especially the youth and wants to establish the impact that mobile devices have in this age group. Secondly, the author wants to find out The reasons which have made mobile technology have a significant impact on people's culture.

\subsubsection{Primary Objective}

The primary aims of the study are several, and they include: To find out the impact of mobile technology on people's livelihoods. Also, another objective it to know whether it was socially acceptable always to use mobile phones in social gatherings.

\subsection{Limitations of the study}

Limitations of this study are likely to be an unequal distribution of participants. For effective finds and conclusions, the research found it of utmost importance that there would be a fair distribution of participants for the results to be credible.

\subsection{Literature Review}

There are quite a number of theories that have been derived from mobile technology and are very useful in its role in impacting culture.

\subsubsection{Theory of Learning and Teaching support}

The theory of learning and teaching support helps in explaining that education is a process and it is aided by the use of resources. Mobile devices can be used by the teaching staff in learning as well as providing the relevant course material to the students.Also, mobile technology helps computing and technology students as it makes their work easier.(Riordan and Traxler).Evolution of mobile technology is making things different for people, especially students and books are become obsolete hence causing a dramatic change in the culture of students who are in the intuitions of higher learning. Assignments are submitted online, and that has changed greatly the culture of manually marking the students' books. This has also caused some negative effects because some students rely on technology and they rarely attend class because even classes can be streamed online.

\subsubsection{Theory of Situation}

This theory suggests that learning must take place in an authentic context. This means that learning ought to take place in a real setting, and this enhances the mode of learning. Mobile technology is available and can enhance teaching in schools by ensuring that students are in the right place at the right time hence improving their concentration. This has also had a major impact on culture because it has revolutionized the way teachers and students think in terms of culture.

\subsubsection{Theory of collaboration}

Collaborative learning has been made possible through the use of computers as well as mobile technology. According to Vygotsky, we learn effectively and efficiently by collaborating with others and also during group work. In fact, he argues that instructional learning had changed the culture of students and It had a significant effect on knowledge construction. Therefore, mobile technology has acted as a mobilization tool for all students to come together and work on a particular task. This has, in turn, promoted a deeper understanding of the matter thereby promoting constructive thinking.

\section{DISCUSSION}

The study sought out to determine the impact of mobile technology on cultures. After conducting a survey on the use of mobile phones in social places, the majority of the respondents agreed that they used their phones frequently in the social areas. The social areas included in public gatherings or functions. That primarily showed that people were no longer respectful of the social places and were using their mobile devices anywhere. In that case, it can be noted and concluded the people no longer have respect for the culture norms and taboo of the society. The above conclusion has been made because long ago, people used to respect social places and it was forbidden to use phones or anything else. However, nowadays, everyone including adults spends most of their time staring at their phones thus forgetting about cultural values. A long time ago picking up phones in social places was considered to be a "subordinate activity" (Rosen). 
The study also sought to find out how mobile technology had impacted people's social lives. Technology has made people be more introverts than extroverts. It is evident that today, almost everything can be found on in the internet thereby making it a global village. For example, online shopping can be done just by the click of a button, and money can be transacted online among many things. Mobile technology is good but it has some adverse effects as well, and it has also minimized human interaction. Nowadays, you do not have to visit a bank because banks have adopted technology in that there is mobile banking hence bringing all the banks features to your mobile device. This, therefore, has had a detrimental effect on the lives of people and has made people very anti-social. People have become antisocial because they have all they need on their phone and they think that no one around them matters. All users of Blackberry smartphones have been labeled as electronic pests because they do not talk to anyone near them because they just look at their phone screens (Locher). It can be concluded that mobile technology has some positive impacts such as making the world a global village, but it has also "killed" the social lives of many individuals. It was also discovered that most people were using their mobile phones while driving and that had caused many accidents because people who are constantly on their phones while driving lack proper concentration and therefore, they cannot respond promptly in case of an emergency.

Another objective of this study was to find out whether mobile phones are allowed to be used in social places. This question has elicited a lot of debated as to whether or not mobile devices are allowed. According to (Rosen), during the old times, the use of a mobile phone in social places was a bad activity. For example, if an individual had a gathering with his or her family he was not allowed to use the mobile phone till he was on his own. According to the culture then, it was of utmost importance that people would respect face to face communication. The people then were of the opinion that missed calls would be returned at a later time. Nowadays, in contrast to the old age belief, the modern day people believe that phone calls are so important and urgent such that they should be answered when necessary and face to face communication can be done anytime. Most of the respondents stated that phone calls are supposed to be answered immediately while face to face communication can be done later. The above beliefs by the youth today have caused mobile technology to have a huge impact on our society because of different views.

\subsection{Future Of Mobile Technology And Its Impact On Culture}

Mobile technology is evolving day and day, and nothing can halt the process. The evolution is occurring at a fast rate; in fact, people are breaking the tradition of physical meetings and replacing them with video calls and voice calls. In addition, students are no longer required to attend classes because if they have their mobile devices, they can access class notes and the course outline online. This has increased laziness among the students.Also, the advancement of technology has aided effective communication between the recipient and the sender of the information. In a class setting, the teacher is able to relay communication very fast, and it is able to reach all his or her students at an appropriate time. Technology is seen to develop in such a way that it will be used to design and come up with various ways of living of a certain culture. That will show value for other cultures thereby promoting them and causing them to grow. For example, if arts are the norm of a particular community then technology will improve it by introducing editing features to that art and enhance it causing it to be more marketable. When a product is more marketable, it will be of more value to a community hence making it more valuable economically which will improve the living conditions of that particular culture.

Mobile devices have continued to upgrade for a very long time. It can be concluded that this is inevitable because there are serious technology advancements occurring. Mobile technology is seen to be in tandem with culture because as it changes it also has a direct effect on the culture of a certain community.Nonetheless, the advancement of mobile technology should be prevented from having a detrimental effect on the culture of communities. Many people adapt to the good and bad effects of advancement of mobile technology. Some teens may end up copying the dressing culture of their role models on the internet however morally wrong they are hence eroding their traditional systems. Therefore, the companies responsible for these advancements should ensure that they restrict harmful content from the Internet. This will prevent individuals from compromising their culture with behavior adopted from the internet hence leading to a positive significant effect of the culture.

\section{CONCLUSION}

Mobile technology has been found to have a significant effect on culture. To be precise mobile technology has had a negative impact on the different cultures of the world. On the other hand, mobile technology has had a positive impact on people's lives, and it has changed the way people communicate as well as transact. For example, someone in the United States can send money to someone in Africa and the transaction will be safe and fast and the recipient gets the money in less than 
ten minutes. In the world today, mobile technology and invention are inevitable. However, based on the finds of this study, there is a significant effect between mobile technology and culture. Technology has changed the way the youth address their parents as well as the older generation. The study also established that younger generations were engaged on their mobile devices most of the time they were in social gatherings.

This vice was also found to exist in the workplace because most employees were constantly on their phone thereby denying a chance of interaction with other employees. This was a major point of concern for employers, and most of them express fears of individuals who are always on their mobile phone. Mobile technology has thereby destroyed the employee-employer relations as well as employee-employee relations because there is a little or minimal interaction between them.

Technology and society have been found to be mutually constitutive. (MacKenzie and Wajcman).That implies that society is expected to undergo a paradigm shift as the technology evolves. It is evident that any change in mobile technology must have effects on the culture and the society of a particular nation.

It can be concluded that mobile technology has had some good and bad effects on culture. Some of the good and notable effects are that mobile technology has improved communication and enhanced the exchange of ideas. When two of more cultures meet over the internet, they communicate and exchange information which can be of utmost importance to the other party. In addition, the populace of one culture is able to borrow ideas from each other and vice versa. If these ideas are edifying, then that is a plus for both communities. However, the advancement of mobile technology has eroded some respectful cultures amongst some African communities because they have copied some of the western cultures from the Internet thanks to mobile technology advancement.

\section{RECOMMENDATIONS}

Based on the findings and the conclusion of the study, the research came up with the following recommendations which were seen as important in determining the impact of mobile technology on culture. Individuals should be asked to minimize their mobile device usage in public as well as in public places. However, they should not be coerced in doing so. Everyone has the free will to do whatsoever their mind decides, and this should be done willfully. This will increase work productivity at workplaces and restore the sanity of culture.Also, the mobile technology companies should take the initiative and educate the users on the positive impact and the dangers of using the mobile devices. In other words, the concerned companies should give the users education and guidance on how to use the mobile phones. For instance, they are supposed to inform them on the benefits of mobile technology and how it makes works easier as well as facilitates safe and faster transfer of funds. On the other hand, users should also be informed of the adverse effects that are associated with using mobile technology. Some of the health hazards include; health effects of using a Smartphone for too long, effects of keeping your phone inside your pocket for too long, dangerous effects of always staying on the phone as well as effects of driving while texting. If mobile technology users are made aware of this then, they will avoid the harmful effects, and that will bring normalcy to the cultural decay that is brought by mobile phone technology.

Regarding social websites, institutions of higher learning should try and minimize their students logging into the site. These sites make students not concentrate in class, and therefore they should be blocked from accessing them. When this is done, their social life will be enhanced thereby making them interact with the community in an efficient and effective way. This will also improve their concentration in class because no effort will be placed on the social media websites and all efforts will be channeled into their education thus making them perform better.

People should be educated on the importance of safeguarding their culture. When this is done, technology advancement will not in any way have a major effect on their way of life. Individuals will tend to stick to their cultures and belief system. Finally, the study recommends that institutions of learning should minimize or eradicate the use of mobile technology in schools. In the recent years, many surveys conducted have shown that most students fail to attend classes because of the digitization of learning. For example, a student can miss classes because he or she knows that even if he misses class, the class teacher will send all the notes to their mobile devices.

Besides, mobile technology has made the students not to socialize with their peers thereby leading to less human interactions. Therefore, even if these students are faced with a challenge they cannot handle it because they are used to technology. If these recommendations are implemented, there will be less negative impact of mobile technology in our schools.

Future studies should be conducted on the effect of mobile technology on specific cultures so that there will be a complete analysis of the effects on this specific culture. Various studies have been conducted on the impact of Smartphone's in the society, Social cultural and many other factors. 
Studies should also be conducted to determine the different dimensions of mobile technology and how they affect cultures. Such patterns will help everyone understand the specific effect of each pattern to the society. For instance, the update of technology in Africa is different from the uptake of technology in the United States.

Therefore, a more comprehensive study should be done to establish which specific kinds of cultures and what exact effects do these mobile technologies affect them. This will aid the researchers as well as the mobile technology firms to come up with a lasting solution to the excess and harmful uptake of technology. The study will be suitable for the community and the mobile technology companies.

\section{WORKS CITED}

[1] Kakabadse, A., et al.Techno Addicts: Young person addiction to technology. Ohio, Sigel Press. (2009).

[2] Katz, James E., and Mark Aakhus. Perpetual contact: Mobile communication, private talk,

[3] Public performance. Cambridge University Press, 2002.

[4] Locher, Margaret. "BlackBerry addiction starts at the top." PC World (2007).

[5] MacKenzie, Donald, and Judy Wajcman. "The Social Shaping of Technology: How the Refrigerator Got Its Hum Milton Keynes." (1985).

[6] Pinchot, et al. "How mobile technology is changing our culture." Journal of Information Systems Applied Research 4.1 (2011): 39.

[7] Riordan, et al. "Supporting computing students at risk using blended technologies." 4th Annual LTSN-ICS Conference. 2003.

[8] Rosen, Christine. "Our cell phones, ourselves." The New Atlantis 6 (2004): 2645.

[9] Tenhunen, Sirpa. "Mobile technology in the village: ICTs, culture, and social logistics in India." Journal of the Royal Anthropological Institute 14.3 (2008): 515-534

[10] Vygotsky, Lev Semenovich. "Language and thought." Massachusetts Institute of Technology Press, Ontario, Canada (1962) 